\title{
Study On Setting Method of Flatness Target Curve of SUNDWIG 20-High Mill Considering Target Crown
}

Jianliang Sun ( $\sim$ sunjianliang@ysu.edu.cn )

Yanshan University

Mingze Yan

Yanshan University

Mingyuan Li

Yanshan University

Tongtong Hao

Yanshan University

\section{Research Article}

Keywords: Twenty high-mill, Copper sheet and strip, Support axle group bending deformation, Flatness,

Finite element method

Posted Date: September 7th, 2021

DOl: https://doi.org/10.21203/rs.3.rs-818483/v1

License: (1) (1) This work is licensed under a Creative Commons Attribution 4.0 International License.

Read Full License 


\title{
Study on Setting Method of Flatness Target Curve of SUNDWIG 20-high Mill Considering Target Crown
}

\author{
Jianliang Sun', Mingze Yan', Mingyuan Li'1, Tongtong Hao' \\ ${ }^{1}$ National Engineering Research Center for Equipment and Technology of Cold Rolling Strip, Yanshan University, Qinhuangdao, 066004, China
}

Keywords: Twenty high-mill ; Copper sheet and strip, Support axle group bending deformation, Flatness, Finite element method

Correspondence to: Jianliang Sun / sunjianliang@ysu.edu.cn

\begin{abstract}
The flatness target curve is important in the flatness control theory. The accuracy of flatness target curve is an important factor to determine the load of flatness control means and flatness quality. Aiming at the defect that crown of each pass after rolling cannot be controlled quantitatively in the traditional target curve formulation of cold rolling, a new method considering the target crown was proposed. Specifically, the target crown of each pass can be set by combining the total proportional crown change in hot rolling field to each pass and the instability discrimination model in cold rolling field. the total proportional crown change of incoming material and finished product is allocated to each pass, and the instability discrimination model is applied to ensure the stability of the plate. The purpose of new method is to control of the crown of each pass quantitatively, so that the flatness and thickness of plate can meet the production requirements. Taking SUNDWIG 20-high mill and typical rolling products as an example, the simulation results show that, on the basis of ensuring the flatness and obtaining the minimum available crown after rolling, the model can make the flatness and crown meet the production requirements at the same time and control the crown of each pass after rolling quantitatively by setting the target crown of each pass.
\end{abstract}

\section{Introduction}

Flatness is the bulking extent of the plate, also represents the residual stress distribution. The flatness target curve refers to the flatness control curve established to consider the rolling or subsequent processing requirements [2]. As a primary machine of rolling thin strip, it is important to study the flatness control theory of 20-high mill. The study about flatness control of 20 high-mill is as follows: Zhao [3] improved the unit matrix method for decoupling in the flatness control program of Sendzimir 20high mill. The simulation results showed that the improved method improved the quality of flatness. Zhang et al. [4] established the finite element model of Sendzimir rolling mill, and explored the influence of the flatness control means on the flatness by simulating the rolling process. Liu et al. [5] used the Contact Element Model to calculate the roll system elastic deformation model of 20-high mill and analyzed the influence of the inner intermediate roll's axial shift on the flatness. Dai [6] proposed to use polynomial to fit the pressure between rolls to improve the calculation speed of the flatness prediction model. Yuan et al. [7] established an accurate roll-to-roll flattening model by using the boundary integral equation, and combined with the metal plastic deformation model to predict the rolling of extremely thin strip in 20-high mill. Guo [8] established the finite element model of a new 20-high mill and analyzed the influence of ASU and other flatness control means on the flatness, but this model only simply distributed the rolling force equally.

The above scholars have made many achievements in the aspect of flatness control, but the research on the setting method of flatness target curve is less. Flatness target curve is the benchmark of flatness control. Whether setting flatness target curve is reasonable determines the flatness quality and the response speed of flatness control means to a certain extent. The research status of the flatness target curve in the cold rolling field is as follows: Lin et al. [9] conducted rolling experiments on 
the $1850 \mathrm{~mm}$ single-stand cold rolling line in parameter setting method and section setting method. The results showed that only when there was a big difference between two methods, there would be a big difference in the flatness of the final product. Liu et al. [10] coupled the metal plastic deformation model with the instability discrimination model, and obtained the transverse residual stress distribution when the strip was in critical instability and noncritical instability. The residual stress distribution under this condition was the flatness target curve, and this paper lays a foundation in the flatness target curve theory in China. Sun et al. [11] proposed a converse stepwise independent optimization method for reverse flatness control target. The concrete method was to make each flatness control target independent and avoid the iteration between models to improve the calculation speed. In the process of formulating the flatness target curve, the factors such as the compensation of the transverse temperature distribution and the detection roll deflection change were considered, and the effect was better after the industrial verification. Chen [12] proposed the method of dynamically setting the flatness target curve, which improved the product quality, considering the rolling force and rolling speed fluctuation and plate parameters in the rolling process. Zhao [13] proposed to combine the flatness control ability of the rolling mill with the flatness target curve theory. and in the formulation process, factors such as the installation error compensation of the the detection roll and the transverse temperature were considered. Hao et al. [14] studied the influence of balance stress and non-balance stress flatness target curve on cold-rolled aluminum strip by parameter setting method. The results showed that the crown was mainly controlled in the first few passes, and the flatness was mainly controlled in the final passes. And in the final passes, the aluminum strip with the balance stress flatness target curve was smoother. Zhou et al. [15] used ABAQUS software to calculate the residual stress generated during cooling. The results showed that the transverse temperature gradient had a greater effect on the residual stress than the transverse temperature distribution. Usamentiaga et al. [16] fitted the strip lateral temperature distribution into a shape compensation curve, which was then input into the shape control system to modify the preset shape target curve. Neto and Ayhan [17] found that the coil shape interfered with the flatness control, and worked out the compensation parameters under different strip roll widths and layers. After inputting the compensation parameters into the flatness control system, the actual shape quality can be improved.

According to the literature mentioned above, there are two ways to set the target curve of cold rolling. One is to set the target curve directly by using parameters, and the other is to derive it from the mechanism model. The parameter setting method is more dependent on the guidance of production experience. If the original flatness target curve is still used for new materials and new processes, there may be a large deviation between the actual shape and the target shape, so the parameter setting method has certain limitations. In the method of mechanism model derivation, the principle is that on the principle of ensuring the flatness of each pass is stable, the crown is mainly controlled in the first few passes, the flatness and crown are both considered in the middle passes, and the flatness is mainly controlled in the final passes.

In the field of hot rolling, the setting method of the flatness target curve is based on the plate crown. The Siemens model completes crown distribution according to the entry proportional crown of rough-rolled strip steel, the target proportional crown of finished strip steel, the reduction rate of the proportional crown in each pass and the exit thickness of each pass [18]. Liu et al. [19] proposed to assign the total proportional crown change to each pass according to the ratio of the reduction ratio of each pass to the total reduction ratio, and then calculated the distribution strategy of target plate crown of each pass. Liu et al [20] proposed a crown distribution strategy based on fining-rolling flatness priority. In the existing crown allocation models, the idea of crown distribution is almost the same, that is, firstly, the range of the wave-starting boundary condition is calculated by Shohet discriminant, and then, the crown is redistributed by the proportional crown or crown distribution model at range.

Whether it is cold rolling or hot rolling, flatness is not the only index to evaluate the strip quality, in addition, also includes the plate section uniformity, that is, the magnitude of the plate crown. Therefore, when setting the shape target curve, the mill, the flatness and the crown should be considered at the same time. In this paper, from the crown after rolling of view, a new method of setting flatness target curve of cold rolling in 20-high mill is proposed. Combined with the instability discrimination model, the crown of each pass can be controlled quantitatively on the basis of meeting the flatness requirements by reasonably setting the target crown of each pass.

\section{Basic model of shape target curve of SUNDWIG 20-high mill}

\section{1 the roll system elastic deformation model}

The main methods to study the roll system elastic deformation model include analytical method, influence function method, finite element method, etc. Taking into account the calculation time and accuracy, the commonly used method in engineering is the segmentation model method, also known as the influence function method. The principle of the influence function method is as follows: firstly, the roll is divided into several segments, and each segment element has load and elastic deformation. Then the influence function in mathematics is used to solve the deformation of each roll unit when unit force is applied. Finally, the 
total deformation of the unit can be obtained by adding the contribution of each load to the unit deformation.

It is necessary to divide the roll system elements before using the influence function method. The traditional element division method and Contact Element Model are used to divide the roll system elements usually. The traditional method is more suitable for 2-high, 4-high and 6-high rolling mills because of the less number of roll layers and without considering relative position of each roll body, so the division is relatively simple. However, when the traditional method is used to solve the multi-layer roll system, it will be complex. This shortcoming can be avoided by the Contact Element Model. The Contact Element Model only needs to consider the contact length of the two rolls. There are advantages and disadvantages in both methods, but when the the inner intermediate shifts axially, it won't contact with the adjacent roll absolutely. The Contact Element Model may not divide the edge unit of the work roll, so the edge unit deformation of the work roll can't be calculated.

Therefore, this paper proposes a improved division method that combines the traditional element division method with the Contact Element Model, as shown in Fig. 1. The Contact Element Model is adopted in P-K contact elements and D-K contact elements. The traditional method is adopted in the S-P contact elements and S-Z contact elements. In this way, both the advantages of the Contact Element Model and the traditional method can be applied to the edge unit of the work roll, so that the displacement of each unit on the whole length of the work roll body can be obtained, and whether the edge contact of the upper and lower work roll can be predicted.And the position relationship of each roller in the upper roller system is shown in Fig. 2.

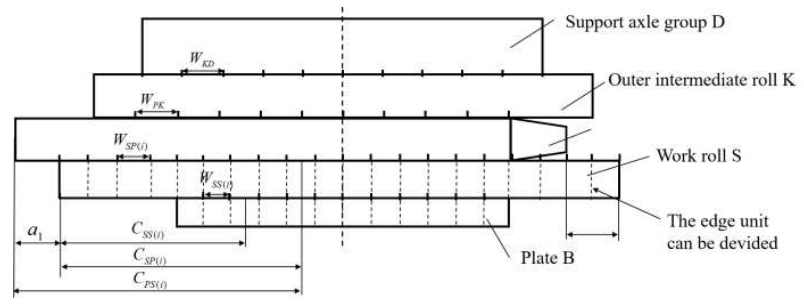

Fig. 1. The improved method combining traditional method and contact element dual coordinate method.

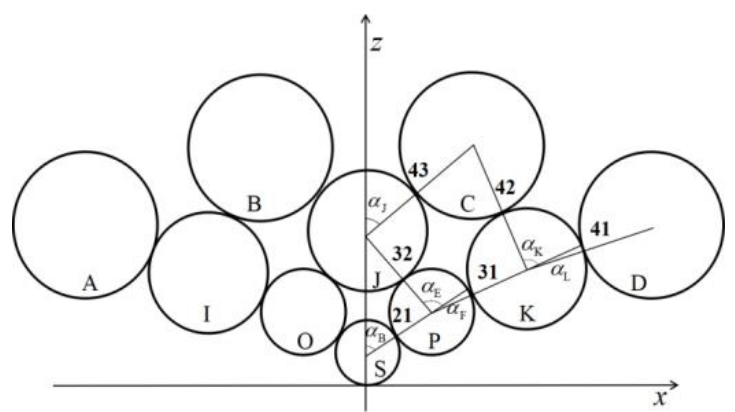

Fig. 2. Position relation of each upper roll system.

In the roll system elastic deformation analysis, each contact element has the same deformation relative to two rolls, so the displacement coordination equation needs to be constructed. Take the $S$ roll as an example, as shown in Eq. (1) :

$$
f_{\mathrm{S} 21(i)}-f_{\mathrm{P} 21(i)}-\Delta_{21(i)}-m_{\mathrm{S}(i)}-m_{\mathrm{P}(i)}=0
$$

Where $f_{\mathrm{S} 21(i)}$ and $f_{\mathrm{P} 21(i)}$ are the deformations of S-P roll units in the direction of 1 and 2 lines, which are calculated by the influence coefficient method; $\Delta_{21(i)}$ is the elastic flattening of S$P$ roll units in the direction of 1 and 2 lines, which can be calculated by Fischer formula; $m_{\mathrm{S}(i)}$ and $m_{\mathrm{P}(i)}$ respectively represent the crown of the roll unit.

Similarly, the displacement coordination equations of the other rolls such as $\mathrm{P}, \mathrm{J}$ and $\mathrm{K}$ contact elements are shown in Eq. (2) Eq.(6):

$$
\begin{aligned}
& f_{\mathrm{P} 32(i)}-f_{\mathrm{J} 32(i)}-\Delta_{32(i)}-m_{\mathrm{P}(i)}-m_{\mathrm{J}(i)}=0 \\
& f_{\mathrm{P} 31(i)}-f_{\mathrm{K} 31(i)}-\Delta_{31(i)}-m_{\mathrm{P}(i)}-m_{\mathrm{K}(i)}=0 \\
& f_{\mathrm{J} 43(i)}-f_{\mathrm{C} 43(i)}-\Delta_{43(i)}-m_{\mathrm{J}(i)}-m_{\mathrm{C}(i)}=0 \\
& f_{\mathrm{K} 42(i)}-f_{\mathrm{C} 42(i)}-\Delta_{42(i)}-m_{\mathrm{K}(i)}-m_{\mathrm{C}(i)}=0 \\
& f_{\mathrm{K} 41(i)}-f_{\mathrm{D} 41(i)}-\Delta_{41(i)}-m_{\mathrm{K}(i)}-m_{\mathrm{D}(i)}=0
\end{aligned}
$$

Based on the previous force analysis of each roll, force and moment equations of each roll in $x$ direction and $z$ direction can be obtained. Take $\mathrm{S}$ roll as an example, force and moment 
equations of $z$ direction are shown in Eq. (7) and Eq. (8) respectively:

$$
\begin{aligned}
& \sum_{i=1}^{N_{\mathrm{SP}}} q_{\mathrm{SP}(i)} W_{\mathrm{SP}(i)} \cos \left(\alpha_{\mathrm{B}}\right) \cdot 2-\sum_{i=1}^{N_{\mathrm{SZ}}} q_{\mathrm{SZ}(i)} W_{\mathrm{SZ}(i)}=0 \\
& \sum_{i=1}^{N_{\mathrm{SP}}} q_{\mathrm{SP}(i)} W_{\mathrm{SP}(i)} \cos \left(\alpha_{\mathrm{B}}\right) C_{\mathrm{SP}(i)} \cdot 2- \\
& \sum_{i=1}^{N_{\mathrm{SZ}}} q_{\mathrm{SZ}(i)} W_{\mathrm{SZ}(i)} C_{\mathrm{SZ}(i)}=0
\end{aligned}
$$

Where $C_{\mathrm{SZ}(i)}$ and $C_{\mathrm{SP}(i)}$ represent the coordinates of $\mathrm{S}-\mathrm{Z}$ and S-P contact elements respectively; $q_{\mathrm{SP}(i)}$ and $q_{\mathrm{SZ}(i)}$ denotes the load of S-P and S-Z contact elements respectively; $W_{\mathrm{SP}}$ and $W_{\mathrm{SZ}}$ denotes the width of S-P and S-Z contact elements respectively.

Similarly, the force and moment equations of $\mathrm{P}, \mathrm{J}$ and $\mathrm{K}$ rolls are shown in Eq. (9) Eq. (18) :

$$
\begin{aligned}
& \sum_{i=1}^{N_{\mathrm{SP}}} q_{\mathrm{SP}(i)} W_{\mathrm{SP}(i)} \sin \left(\alpha_{\mathrm{B}}\right)+ \\
& \sum_{i=1}^{N_{\mathrm{PJ}}} q_{\mathrm{PJ}(i)} W_{\mathrm{PJ}} \sin \left(\alpha_{\mathrm{E}}-\alpha_{\mathrm{B}}\right)- \\
& \sum_{i=1}^{N_{\mathrm{PK}}} q_{\mathrm{PK}(i)} W_{\mathrm{PK}} \cos \left(\pi / 2-\alpha_{\mathrm{B}}-\alpha_{\mathrm{F}}\right)=0 \\
& \sum_{i=1}^{N_{\mathrm{SP}}} q_{\mathrm{SP}(i)} W_{\mathrm{SP}(i)} C_{\mathrm{PS}(i)} \cos \left(\alpha_{\mathrm{B}}\right)- \\
& \sum_{i=1}^{N_{\mathrm{PJ}}} q_{\mathrm{PJ}(i)} W_{\mathrm{PJ}} C_{\mathrm{PJ}(i)} \cos \left(\alpha_{\mathrm{E}}-\alpha_{\mathrm{B}}\right)- \\
& \sum_{i=1}^{N_{\mathrm{PK}}} q_{\mathrm{PK}(i)} W_{\mathrm{PK}} C_{\mathrm{PK}(i)} \cos \left(\alpha_{\mathrm{B}}+\alpha_{\mathrm{F}}\right)= \\
& \sum_{i=1}^{N_{\mathrm{SP}}} q_{\mathrm{SP}(i)} W_{\mathrm{SP}(i)} \cos \left(\alpha_{\mathrm{B}}\right)- \\
& \sum_{i=1}^{N_{\mathrm{PJ}}} q_{\mathrm{PJ}(i)} W_{\mathrm{PJ}} \cos \left(\alpha_{\mathrm{E}}-\alpha_{\mathrm{B}}\right)- \\
& \sum_{i=1}^{N_{\mathrm{PK}}} q_{\mathrm{PK}(i)} W_{\mathrm{PK}} \cos \left(\alpha_{\mathrm{B}}+\alpha_{\mathrm{F}}\right)=0
\end{aligned}
$$

$$
\begin{aligned}
& \sum_{i=1}^{N_{\mathrm{SP}}} q_{\mathrm{SP}(i)} W_{\mathrm{SP}(i)} C_{\mathrm{PS}(i)} \cos \left(\alpha_{\mathrm{B}}\right)- \\
& \sum_{i=1}^{N_{\mathrm{PJ}}} q_{\mathrm{PJ}(i)} W_{\mathrm{PJ}} C_{\mathrm{PJ}(i)} \cos \left(\alpha_{\mathrm{E}}-\alpha_{\mathrm{B}}\right)- \\
& \sum_{i=1}^{N_{\mathrm{PK}}} q_{\mathrm{PK}(i)} W_{\mathrm{PK}} C_{\mathrm{PK}(i)} \cos \left(\alpha_{\mathrm{B}}+\alpha_{\mathrm{F}}\right)=0
\end{aligned}
$$

$\sum_{i=1}^{N_{\mathrm{JC}}} q_{\mathrm{JC}(i)} W_{\mathrm{JC}} \cos \left(\alpha_{\mathrm{J}}\right) \cdot 2=0$

$$
\begin{aligned}
& \sum_{i=1}^{N_{\mathrm{PJ}}} q_{\mathrm{PJ}(i)} W_{\mathrm{PJ}} C_{\mathrm{JP}(i)} \cos \left(\alpha_{\mathrm{E}}-\alpha_{\mathrm{B}}\right) \cdot 2- \\
& \sum_{i=1}^{N_{\mathrm{JC}}} q_{\mathrm{JC}(i)} W_{\mathrm{JC}} C_{\mathrm{JC}(i)} \cos \left(\alpha_{\mathrm{J}}\right) \cdot 2=0
\end{aligned}
$$

$$
\begin{aligned}
& \sum_{i=1}^{N_{\mathrm{KC}}} q_{\mathrm{KC}(i)} W_{\mathrm{KC}} \sin \left(\alpha_{\mathrm{K}}-\alpha_{\mathrm{B}}-\alpha_{\mathrm{F}}\right)+ \\
& \sum_{i=1}^{N_{\mathrm{PK}}} q_{\mathrm{PK}(i)} W_{\mathrm{PK}} \cos \left(\pi / 2-\alpha_{\mathrm{B}}-\alpha_{\mathrm{F}}\right)- \\
& \sum_{i=1}^{N_{\mathrm{KD}}} q_{\mathrm{KD}(i)} W_{\mathrm{KD}} \sin \left(\alpha_{\mathrm{B}}+\alpha_{\mathrm{F}}+\alpha_{\mathrm{L}}\right)=0
\end{aligned}
$$

$$
\begin{aligned}
& \sum_{i=1}^{N_{\mathrm{KC}}} q_{\mathrm{KC}(i)} W_{\mathrm{KC}} C_{\mathrm{KC}(i)} \sin \left(\alpha_{\mathrm{K}}-\alpha_{\mathrm{B}}-\alpha_{\mathrm{F}}\right)+ \\
& \sum_{i=1}^{N_{\mathrm{PK}}} q_{\mathrm{PK}(i)} W_{\mathrm{PK}} C_{\mathrm{KP}(i)} \cos \left(\pi / 2-\alpha_{\mathrm{B}}-\alpha_{\mathrm{F}}\right)- \\
& \sum_{i=1}^{N_{\mathrm{KD}}} q_{\mathrm{KD}(i)} W_{\mathrm{KD}} C_{\mathrm{KD}(i)} \sin \left(\alpha_{\mathrm{B}}+\alpha_{\mathrm{F}}+\alpha_{\mathrm{L}}\right)=0
\end{aligned}
$$

$$
\begin{aligned}
& \sum_{i=1}^{N_{\mathrm{KC}}} q_{\mathrm{KC}(i)} W_{\mathrm{KC}} \cos \left(\alpha_{\mathrm{K}}-\alpha_{\mathrm{B}}-\alpha_{\mathrm{F}}\right)- \\
& \sum_{i=1}^{N_{\mathrm{PK}}} q_{\mathrm{PK}(i)} W_{\mathrm{PK}} \sin \left(\pi / 2-\alpha_{\mathrm{B}}-\alpha_{\mathrm{F}}\right)+ \\
& \sum_{i=1}^{N_{\mathrm{KD}}} q_{\mathrm{KD}(i)} W_{\mathrm{KD}} \cos \left(\alpha_{\mathrm{B}}+\alpha_{\mathrm{F}}+\alpha_{\mathrm{L}}\right)=0
\end{aligned}
$$




$$
\begin{aligned}
& \sum_{i=1}^{N_{\mathrm{KC}}} q_{\mathrm{KC}(i)} W_{\mathrm{KC}} C_{\mathrm{KC}(i)} \cos \left(\alpha_{\mathrm{K}}-\alpha_{\mathrm{B}}-\alpha_{\mathrm{F}}\right)- \\
& \sum_{i=1}^{N_{\mathrm{PK}}} q_{\mathrm{PK}(i)} W_{\mathrm{PK}} C_{\mathrm{KP}(i)} \sin \left(\pi / 2-\alpha_{\mathrm{B}}-\alpha_{\mathrm{F}}\right)+ \\
& \sum_{i=1}^{N_{\mathrm{KD}}} q_{\mathrm{KD}(i)} W_{\mathrm{KD}} C_{\mathrm{KD}(i)} \cos \left(\alpha_{\mathrm{B}}+\alpha_{\mathrm{F}}+\alpha_{\mathrm{L}}\right)=0
\end{aligned}
$$

Eq. (9) Eq. (18) can be used to obtain equation group whose unknowns are the load of the contact unit between each roll and the rigid displacement at both ends of each roll. There are ( $N_{\mathrm{SP}}$ $\left.+N_{\mathrm{PJ}}+N_{\mathrm{PK}}+N_{\mathrm{JC}}+N_{\mathrm{KC}}+N_{\mathrm{KD}}+12\right)$ unknowns. The flattening quantity of each roll contains the load of the contact element between rolls, so the equation group needs to be solved iteratively.

\section{2 the Metal plastic deformation model}

The calculation methods of metal plastic deformation model are mainly includes strip element method, boundary element method, variational method, strip element variational method, etc. The strip element variational method is widely used in engineering calculation because it combines the advantages of the strip element method and the variational method. Fig. 3 is the schematic diagram of strip division. In this paper, the strip element variational method in reference [21] is used to calculate the distribution of the exit and entrance tensile stress of the strip.

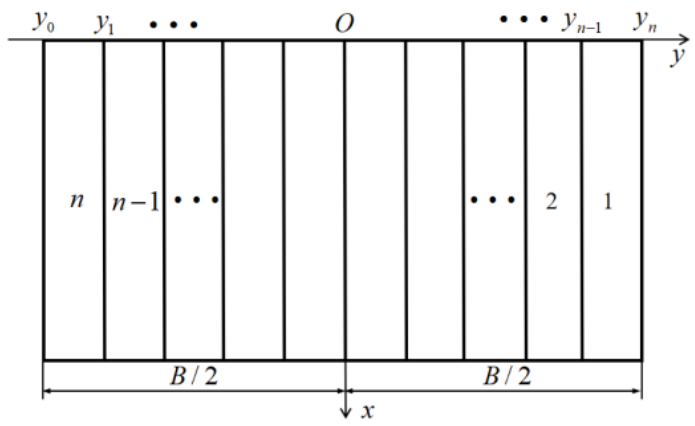

Fig. 3. Schematic diagram of variational method.

The exit tensile stress model $\sigma_{1(i)}(y)$ in reference [22] is shown in Eq. (19) :

$$
\begin{aligned}
& \sigma_{1(i)}(y)=\frac{T_{1}}{B \overline{h_{1}}}+\frac{E}{1-v^{2}}\left[1+\frac{h_{1(i)}}{\bar{h}_{1}}-\frac{h_{0(i)}}{\bar{h}_{0}}-\frac{l_{0(i)}}{\bar{l}_{0}}\right. \\
& \left.+u^{\prime}(y)-\frac{u(B / 2)-u(-B / 2)}{B}\right] \quad i=(1,2, \cdots, n)
\end{aligned}
$$

Where $T_{1}$ is the exit tension; $B$ is the width of plate; $\overline{h_{0}}$ and $\overline{h_{1}}$ represent the average entry and exit thickness respectively; $h_{0(i)}$ and $h_{1(i)}$ the entry thickness and exit thickness of each element; $l_{0(i)}$ and $\overline{l_{0}}$ represent each element incoming material length and its mean value respectively; $u(y)$ is the transverse displacement function of the outlet on the bar element.

The entry tensile stress model $\sigma_{0(i)}(y)$ in reference [22] is shown in Eq. (20) :

$$
\sigma_{0(i)}(y)=\overline{\sigma_{0}}+\frac{E}{1-v^{2}}\left[\frac{\overline{h_{0}} h_{1(i)}\left(1+u^{\prime}(y)\right)}{\overline{h_{1}} h_{0(i)}\left(1+\frac{u_{\mathrm{n}}-u_{1}}{B}\right)}-\frac{l_{0(i)}}{\overline{l_{0}}}\right]
$$

Where $\overline{\sigma_{0}}$ is the average entry tensile stress (GPa).

\section{3 the Instability discrimination model}

According to the metal plastic deformation model in 2.2, the exit tensile stress distribution of the strip can be obtained. After removing the average exit tensile stress, the residual stress distribution can be obtained, as shown in Eq. (21):

$$
\sigma_{x}(y)=\sigma_{1}(y)-\overline{\sigma_{1}}(y)
$$

Where $\sigma_{1}(y)$ is the exit tensile stress; $\overline{\sigma_{1}}(y)$ is the average exit tensile stress.

The residual stress meets the self-phase equilibrium condition, that is, the integral of residual stress along the width of the plate is 0 , as shown in Eq. (22):

$$
\int_{-B / 2}^{B / 2} \sigma_{x}(y) d y=0
$$

Figure 4 shows the strip element discriminant model. After 
slicing the strip along the width direction, a strip of length $l$ is intercepted. There is equal opposite longitudinal load in the $x$ direction of the two sides, which is namely residual stress $\sigma_{x}(y)$.

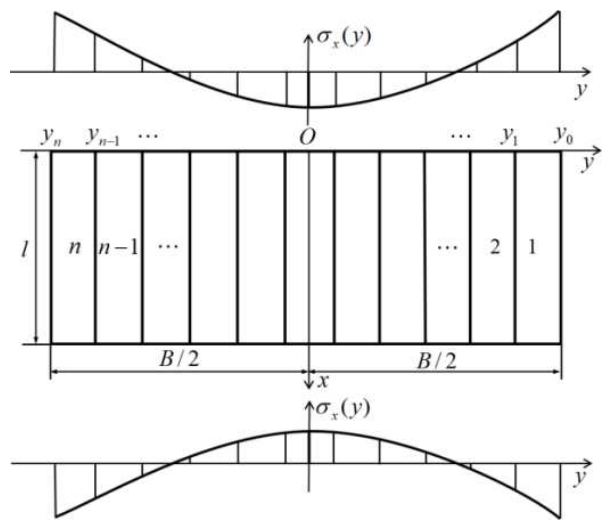

Fig. 4. The strip element discriminant model.

The basic principle of the instability discrimination model is as follows: firstly, figure out the residual stress distribution along the width direction of plate; Secondly, based on the theory of small deflection, the classic buckling theory is used to figure out the flatness defect or instability degree, and the result is used to measure whether the strip meets the production requirements. This section use the instability discrimination model established in reference [23] to solve the discrimination factor, with the purpose of determining the energy state of the strip, that is, whether the flatness quality is good or not.

In order to judge the energy state of the strip, it is necessary to know its residual stress distribution $\sigma_{x}^{*}(y)$ in the critical stable state, which can be expressed by Eq. (23):

$$
\sigma_{x}^{*}(y)=\xi \sigma_{x}(y)
$$

Where $\xi$ is discriminant factor.

Different $\xi$ correspond to different flatness states, as shown in Table 1 :

Table 1. roll parameters

\begin{tabular}{l|l} 
Discriminant factor & Flatness condition \\
\hline
\end{tabular}

\begin{tabular}{c|c}
\hline$\xi<1$ & Stable buckling, poor shape \\
\hline$\xi=1$ & Critical buckling \\
\hline$\xi>1$ & No loss of stability, good shape \\
\hline
\end{tabular}

\section{Optimization of flatness target curve considering target crown}

\section{1 the Instability discrimination model}

In the literature [13], only the rolling mill and the flatness are considered, specifically, the roll system elastic deformation, the metal plastic deformation model and the instability discrimination model are combined together, and the discriminant factor can be optimized to meet the preset requirements by the flatness control means. After reaching the limit of the mill flatness control ability, if the discriminant factor is still not available in the convergence range, it proves that the target flatness has exceeded the range of the mill flatness control ability, then the discriminant factor needs to be reset. The specific idea is shown in Figure 5.

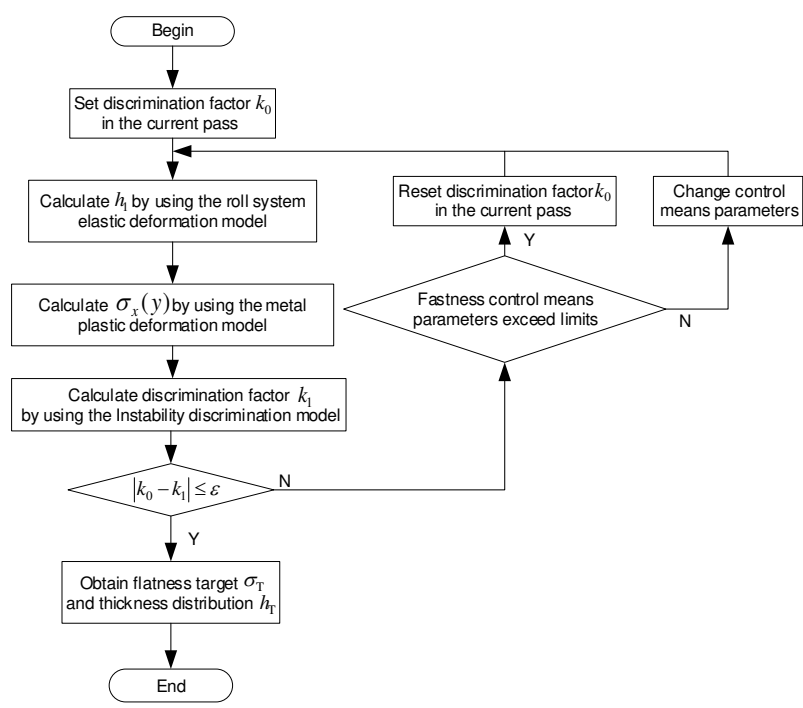

Fig. 5. The idea of setting the flatness target curve considering the flatness control ability of the rolling mill

\subsection{Optimization idea of flatness target curve considering target crown}

As mentioned in the introduction, when setting flatness target curve the most basic principle is to ensure the plate of each pass stable. the determination of the flatness target curve should be 
based on three factors: rolling mill, flatness and crown. the flatness and the plate section shape have a corresponding relationship, The section shape corresponds to the crown of the plate. Therefore, the overall idea of this paper is as follows:

(1) Firstly, according to the incoming crown and the preset target crown value of the final pass, the total crown change is allocated to each pass and calculated to obtain the target crown of each pass;

(2) Secondly, flatness prediction model is used to get the exit thickness distribution and residual stress distribution, the residual stress can be calculated by the Instability discrimination model. And then judge whether crown and discriminant factor of each pass meet the requirements. If they doesn't meet the requirements, then change the flatness control means parameters to calculate again until the requirements are met. And if they meet the requirements, then begin the calculation of next pass;

(3) Finally, when all the flatness control means reach the limit value andt the ideal crown and flatness after rolling are still not obtained, it is proved that the crown control ability of the rolling mill in this pass has reached the limit under the condition of ensuring the strip stability, then the target crown needs to be reset. The specific process of the flatness target curve formulation method considering target crown proposed in this paper is shown in Fig. 6.

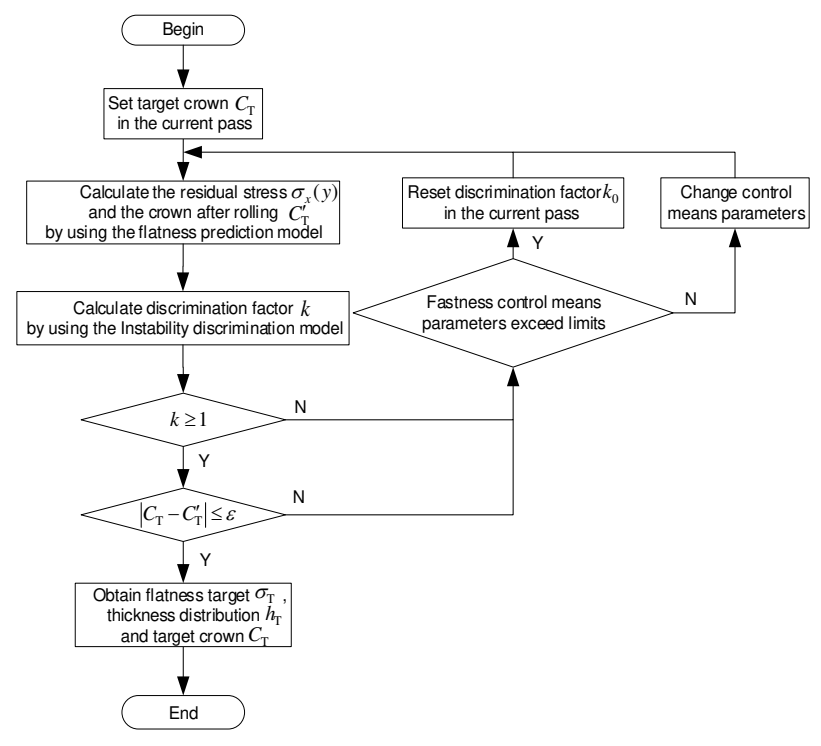

Fig. 6 . The idea of setting the flatness target curve considering the target crown.

The difference between the incoming proportional crown and the target proportional crown is distributed according to the proportion of the reduction ratio of each pass to the total reduction ratio in the literature [18]. Suppose that there are $n$ passes in this process, the crown distribution model is shown in Eq. (24) to Eq. (26) :

$$
\begin{aligned}
& \varepsilon_{i}=\frac{h_{\mathrm{f}(i)}-h_{\mathrm{b}(i)}}{h_{\mathrm{f}(i)}} \\
& \Delta C_{\mathrm{p}(i)}=\Delta C_{\mathrm{p}} \varepsilon_{i} / \sum_{i=1}^{n} \varepsilon_{i} \\
& C_{\mathrm{b}(i)}=\left(\Delta C_{\mathrm{p}(i)}+\frac{C_{\mathrm{f}(i)}}{h_{\mathrm{f}(i)}}\right) h_{\mathrm{b}(i)}
\end{aligned}
$$

Where $h_{\mathrm{f}(i)}$ and $h_{\mathrm{b}(i)}$ represent the thickness before rolling $(\mathrm{mm})$ and after rolling $(\mathrm{mm})$ of each pass; $\varepsilon_{i}$ is the reduction rate of each pass; $\Delta C_{\mathrm{p}(i)}$ is proportional crown variation of each pass; $\Delta C_{\mathrm{b}(i)}$ is target crown $(\mathrm{mm})$ after rolling of each pass.

\section{Results analysis and discussion}

\subsection{SUNDWIG 20-high mill and rolling parame- ters of a factory}

In this section, SUNDWIG 20-high mill of a factory is taken as the research object. The upper stand can be moved up and down along the column to achieve lift or push down operation, which is more flexible than the push down operation of the Sendzimir mill using rack and pinion drive. The flatness control means of the mill mainly include the following three kinds: the inner intermediate roll axial shift, the support axle group bending deformation and the roll tilting. The most width of the main rolled products is $650 \mathrm{~mm}$, and the thickness is between $0.5-1.35 \mathrm{~mm}$.

The roll system of SUNDWIG 20-high mill is shown in Fig 7. Table 2 is the parameters of each roll.

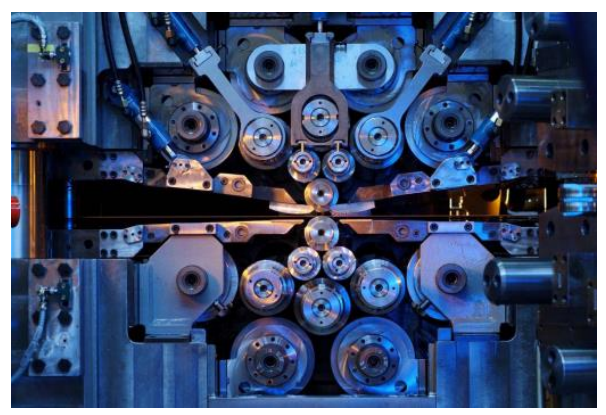


Table 4. Preset values of flatness control means.

Fig. 7. The roll system of SUNDWIG 20-high mill.

Table 2. Material properties of roll system

\begin{tabular}{c|c|c|c}
\hline \multirow{2}{*}{ Name } & \multicolumn{2}{|c}{ Parameters } \\
\cline { 2 - 3 } & $\begin{array}{c}\text { Magnitude } \\
(\mathrm{mm})\end{array}$ & $\begin{array}{c}\text { Young's modulus } \\
(\mathrm{GPa})\end{array}$ & $\begin{array}{c}\text { Poisson's } \\
\text { ratio }\end{array}$ \\
\hline S roll & $\$ 90 \times 810$ & 540 & \multirow{2}{*}{0} \\
\hline P roll & $\$ 90 \times 810$ & 210 & \multirow{2}{*}{0.3} \\
\hline J roll & $\$ 150 \times 750$ & 210 & \multirow{2}{*}{} \\
\hline K roll & $\Phi 145 \times 750$ & 210 & \\
\hline C, D roll & $\Phi 220 \times 730$ & 210 & \\
\hline
\end{tabular}

\subsection{Comparison of traditional ideas and idea in this paper}

According to the proposed method about flatness target curve in this paper, the three passes $650 \mathrm{~mm}$ product of a factory are respectively calculated by adopting the traditional "first convexity and then shape" and the idea in this paper. And the calculation results are compared to verify whether the idea in this paper is reasonable. The product's incoming crown is $13.5 \mu \mathrm{m}$, its elastic modulus and Poisson's are $115 \mathrm{GPa}$ and 0.34 respectively. Other detailed process parameters and preset values of shape control means are shown in Table 3 and Table 4.

Table 3. product parameters

\begin{tabular}{c|c|c|c}
\hline Pass number & 1 & 2 & 3 \\
\hline Entrance thickness(mm) & 0.7 & 0.433 & 0.315 \\
\hline Exit thickness(mm) & 0.433 & 0.315 & 0.240 \\
\hline Friction coefficients & 0.05 & 0.05 & 0.05 \\
\hline Exit tension(kN) & 29.37 & 21.50 & 18.97 \\
\hline Entrance tension(kN) & 18.15 & 18.57 & 15.43 \\
\hline Deformation resistance(GPa) & 0.320 & 0.365 & 0.392 \\
\hline
\end{tabular}

\begin{tabular}{c|c|c|c}
\hline Pass number & 1 & 2 & 3 \\
\hline Axial shifting value $(\mathrm{mm})$ & -17.2 & -20.4 & -22.8 \\
\hline Saddle displacement(mm) & $0,0,0,0$ & $0,0,0,0$ & $0,0,0,0$ \\
\hline
\end{tabular}

Firstly, the traditional "crown first then flatness" approach as shown in Fig. 5 was used to calculate the actual crown of the final pass after rolling with a critical good flatness, it was 5.11 $\mu \mathrm{m}$. Then, the target crown of each pass was deduced adversely using Eq. (24) to Eq. (26), and the crown calculation results are shown in Table 5.

Table 5. Setting value of target crown after each pass rolling is proposed in this paper.

\begin{tabular}{c|c|c|c}
\hline Pass number & 1 & 2 & 3 \\
\hline $\begin{array}{c}\text { Setting value of target crown } \\
\text { in this paper(mm) }\end{array}$ & 8.72 & 6.54 & 5.11 \\
\hline
\end{tabular}

In practice, the flatness target curve is usually axisymmetric on both sides of the center of the mill. Because there are too many distractions such as vibration and precision of equipments. If asymmetric flatness is desired, it can be adjusted by asymmetric flatness adjustment means in the production process, and the bending deformation of upper roll system $A$ and $D$ support axle group of SUNDWIG 20-high mill is asymmetric flatness adjustment means. Therefore, in the calculation of this paper, the bending deformation function of $A$ and $D$ support axle group does not participate in the optimization process of the parameters of the flatness adjustment means, the inner intermediate roll is the only one flatness adjustment means.

The data given in Tables 3 to Tables 5 are used to calculate the flatness target curve, and the results are shown in Fig. 8 to Fig. 10. Method 1 and method 2 denote the traditional method and the method in this paper. In Fig. 8 to Fig. 10, each flatness target curve is symmetric about the plate center line, meeting the principle of self-phase equilibrium of residual stress, that is, the integral of residual stress along the width of the strip is 0 . It can be seen that different target curves can be obtained in each pass when different target crown is applied.

In Fig. 8, difference of the crown after rolling difference between two ideas is $0.08 \mu \mathrm{m}$ in the first pass, and the flatness target curve is almost the same. 

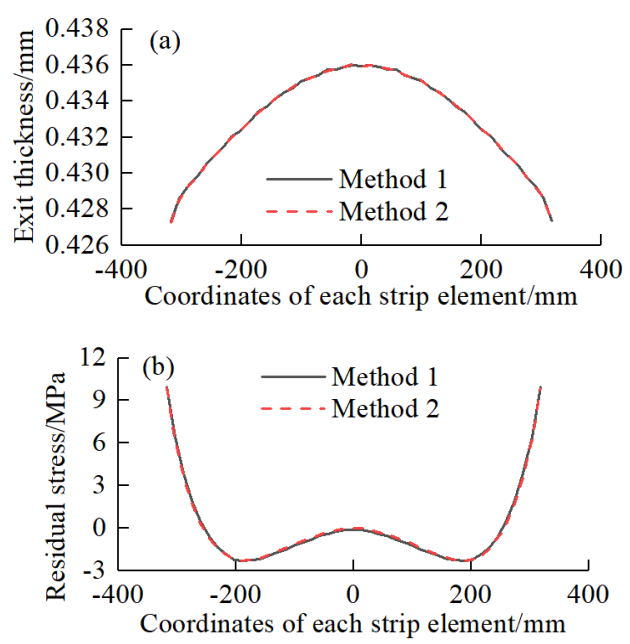

Fig. 8. Simulation results of the first pass

In Fig. 9, Although the thickness of the second pass is almost the same, after applying the target crown, the exit crown difference is $0.13 \mu \mathrm{m}$, and the edge strip element residual stress difference is $0.22 \mathrm{MPa}$. It proves that target crown can influence flatness to some extent.
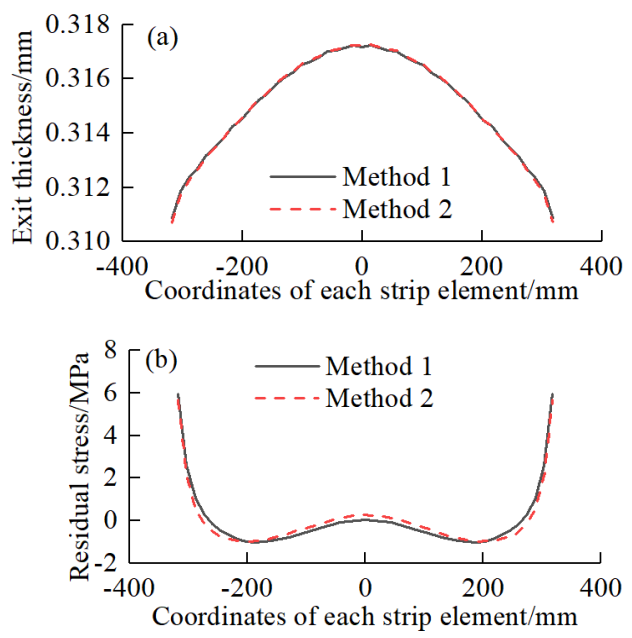

Fig. 9. Simulation results of the second pass.

In Fig. 10, the crown after rolling is almost the same in the final pass, but the amplitude of residual stress at the edge strip ele- ment varies by $0.52 \mathrm{MPa}$. This is because the thickness distribution in the third pass is different in two ideas, which leads to different reduction magnitude of residual stress of each strip element.

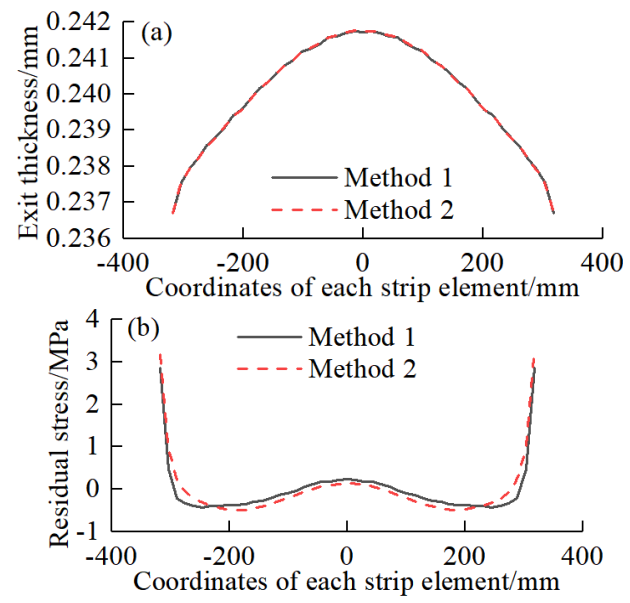

Fig. 10. Simulation results of the final pass.

After the optimization of the flatness prediction model, the adjustment value of the flatness control means and the actual crown value of each pass are shown in Table 6 and Table 7 respectively. By comparing Table 5 and Table 7, the maximum difference between the target crown and the actual crown after rolling is only $0.02 \mu \mathrm{m}$, which indicates that the improved method is reasonable. The crown after rolling can be controlled quantitatively by presetting the target crown of each pass under the condition that the flatness is good.

Table 6. Optimized value of flatness control means.

\begin{tabular}{c|c|c|c}
\hline Pass number & 1 & 2 & 3 \\
\hline Roll Axial shift & -27.4 & -26.4 & -25.2 \\
in traditional idea(mm) & & & \\
\hline $\begin{array}{c}\text { Roll Axial shift } \\
\text { in this paper(mm) }\end{array}$ & -27.2 & -26.0 & -25.6 \\
\hline
\end{tabular}

Table7. Actual crown value of each pass after rolling. 


\begin{tabular}{c|c|c|c}
\hline Pass number & 1 & 2 & 3 \\
\hline $\begin{array}{c}\text { The crown } \\
\text { in traditional idea }(\mu \mathrm{m})\end{array}$ & 8.66 & 6.43 & 5.11 \\
\hline $\begin{array}{c}\text { The crown } \\
\text { in this paper }(\mu \mathrm{m})\end{array}$ & 8.74 & 6.53 & 5.12 \\
\hline
\end{tabular}

For two different ideas, the common point is that with the increase of passes, the crown after rolling becomes smaller and smaller, the section shape becomes more uniform, the amplitude of residual stress becomes smaller, and the plate tends to be straight.

\subsection{Calculation of flatness target curve with dif- ferent target crown}

According to the results in 4.2, as long as the target crown of the final pass is reasonably set, then the flatness target curve with controllable crown after rolling in each pass can be obtained. In the whole rolling schedule, the best operation is to control the plate as "flat" and "straight", that is, the crown after rolling is 0 , and the residual stress distribution is relatively uniform. But the flatness and thickness of the plate are two contradictory existence, if blindly eliminate the crown will make the flatness is poor, but considering the flatness only will make the crown not ideal too. Therefore, it is necessary to find a "balance point" between flatness and thickness. At this "balance point", Flatness and thickness are both meet the products requirements.

In this section, firstly, make sure what the minimum crown of the final pass is. Taking the data in Table 3 and Table 4 as an example, the target crown of the third pass is set as $C_{3}=0 \mu \mathrm{m}$. According to Eq. (24) to Eq. (26), $C_{2}=1.62 \mu \mathrm{m}$ and $C_{1}=4.78$ $\mu \mathrm{m}$ can be obtained. Combined with the instability discrimination model, the actual crown value of three passes is calculated as $C_{1}=8.66 \mu \mathrm{m}, C_{2}=6.16 \mu \mathrm{m}, C_{3}=4.55 \mu \mathrm{m}$, that is, the crown after rolling under the condition that the plate is stable in three passes. For comparison, the target crown of the final pass in each simulation condition were set as $5.00 \mu \mathrm{m}, 5.50 \mu \mathrm{m}$ and $6.00 \mu \mathrm{m}$ respectively. And the target crown of other passes can be deduced adversely by using Eq. (24) to Eq. (26). The setting values of target crown of each pass is shown in Table 8.

Table 8. Setting values of target crown of each pass in this paper.

\begin{tabular}{c|c|c|c}
\hline Pass number & 1 & 2 & 3 \\
\hline The crown in simulation $1(\mu \mathrm{m})$ & 8.63 & 6.43 & 5.00 \\
\hline
\end{tabular}

\begin{tabular}{c|c|c|c}
\hline The crown in simulation 2 $(\mu \mathrm{m})$ & 9.02 & 6.91 & 5.50 \\
\hline The crown in simulation 3( $\mu \mathrm{m})$ & 9.41 & 7.39 & 6.00 \\
\hline
\end{tabular}

The simulation results are shown in Fig. 11 Fig. 13. In Fig. 11, As the setting values of target crown of final pass increases from $5.00 \mu \mathrm{m}$ to $6 \mu \mathrm{m}$, the crown changes from $8.66 \mu \mathrm{m}$ to $9.42 \mu \mathrm{m}$. The residual stress in the middle of the plate is from $-0.415 \mathrm{MPa}$ to $0.947 \mathrm{MPa}$, and it changes from $9.969 \mathrm{MPa}$ to $9.060 \mathrm{MPa}$ in the edge.
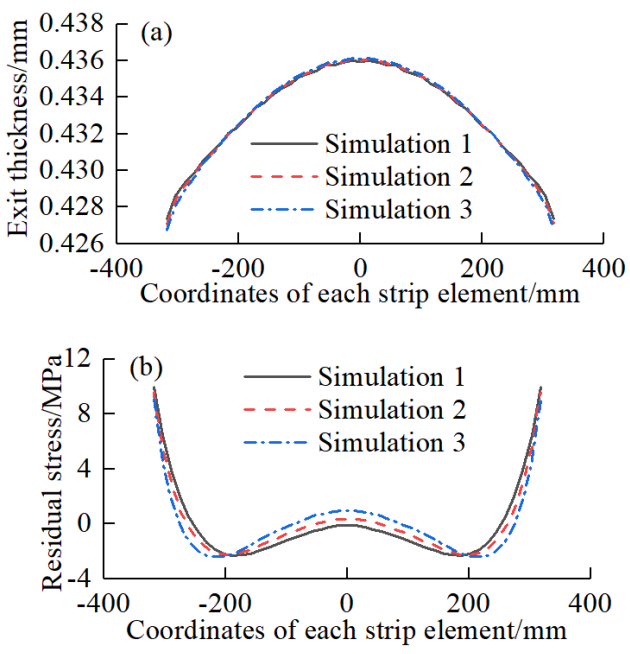

Fig. 11. Simulation results of the first pass.

In Fig. 12, As the setting values of target crown of final pass increases from $5.00 \mu \mathrm{m}$ to $6 \mu \mathrm{m}$, the crown changes from 6.43 $\mu \mathrm{m}$ to $7.28 \mu \mathrm{m}$. The residual stress in the middle of the plate is from $0.053 \mathrm{MPa}$ to $0.963 \mathrm{MPa}$, and it changes from $5.938 \mathrm{MPa}$ to $5.261 \mathrm{MPa}$ in the edge.

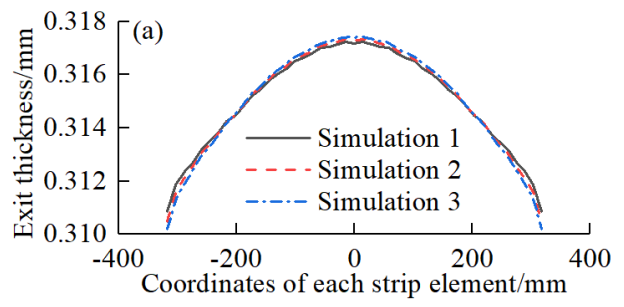




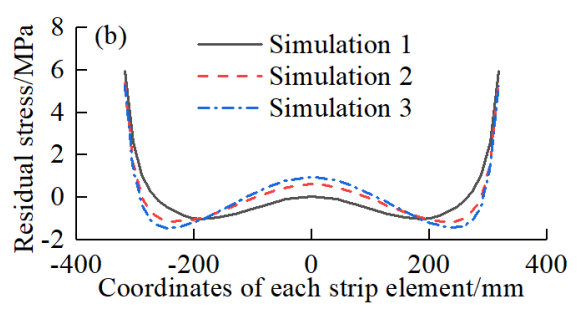

Fig. 12. Simulation results of the second pass.

In Fig. 13, As the setting values of target crown of final pass increases from $5.00 \mu \mathrm{m}$ to $6 \mu \mathrm{m}$, the crown changes from 5.00 $\mu \mathrm{m}$ to $5.49 \mu \mathrm{m}$. The residual stress in the middle of the plate is from $0.129 \mathrm{MPa}$ to $0.047 \mathrm{MPa}$, and it changes from $3.143 \mathrm{MPa}$ to $3.612 \mathrm{MPa}$ in the edge. And The residual stress at 1/4 plate decreases, the rib wave trend of the final pass is aggravated, but the flatness change of the middle plate is small.
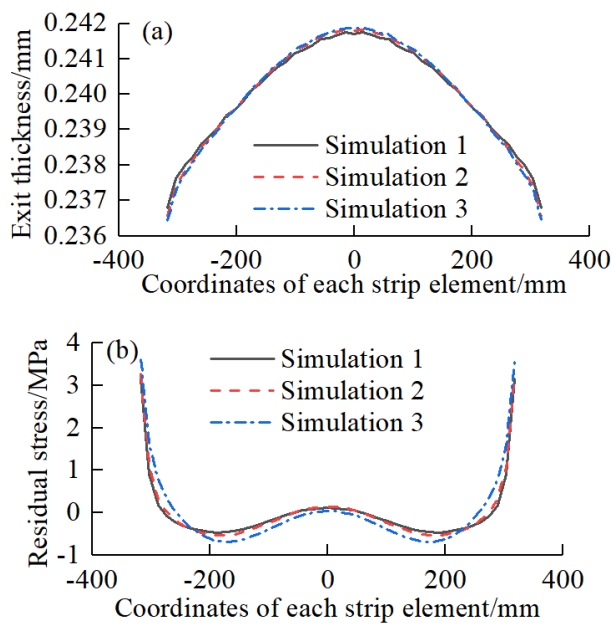

Fig. 13. Simulation results of the final pass.

The optimal value of the flatness control means and the actual crown value of each pass with the flatness prediction model optimization are shown in Table 9 and Table 10 respectively. In Table 10, when the final pass target of simulation 2 is $5.50 \mu \mathrm{m}$, and strip is stable in the third pass, the actual crown after rolling is obtained to be $5.33 \mu \mathrm{m}$. However, in the simulation 3, when the final pass target crown is $6.00 \mu \mathrm{m}$ and strip is stable in the second pass, the actual crown after rolling is calculated to be $7.28 \mu \mathrm{m}$. And it leads to the difference of $0.17 \mu \mathrm{m}$ between the final pass crown and target crown in simulation 2, and $0.51 \mu \mathrm{m}$ between the final pass crown and target crown in simulation 3 . However, in the simulation 1, the crown of each pass can be controlled quantitatively.

Table 9. Optimized value of flatness control means.

\begin{tabular}{c|c|c|c}
\hline Pass number & 1 & 2 & 3 \\
\hline Simulation 1(mm) & -27.4 & -25.6 & -26.0 \\
\hline Simulation 2(mm) & -26.6 & -25.4 & -25.0 \\
\hline Simulation 3(mm) & -25.6 & -24.8 & -25.0 \\
\hline
\end{tabular}

Table10. Actual crown value of each pass after rolling.

\begin{tabular}{|c|c|c|c|}
\hline Pass number & 1 & 2 & 3 \\
\hline Simulation $1(\mu \mathrm{m})$ & 8.66 & 6.43 & 5.00 \\
\hline Simulation $2(\mu \mathrm{m})$ & 9.00 & 6.91 & $5.33^{*}$ \\
\hline Simulation $3(\mu \mathrm{m})$ & 9.42 & $7.28^{*}$ & 5.49 \\
\hline
\end{tabular}

Note: the font marked with "*" in the table refers to the crown value obtained when the strip is close to instability in the current pass.

\section{Conclusions}

(1) In this paper, combining the characteristics of cold rolling and hot rolling, the rolling mill, the flatness and the crown, that is, combining the roll system elastic deformation model, the metal plastic deformation model and the instability identification model can obtain the method of setting the flatness target curve considering the target crown.

(2) Combined with the instability discrimination model, the minimum roll crown of a specific type of mill can be determined, the final pass target crown can be selected according to the minimum roll crown. The simulation results show that by setting the target crown of the final pass reasonably, the crown of each pass after rolling can be controlled quantitatively on the basis of ensuring the stable strip, and the comprehensive control of the flatness and crown of the strip can be achieved.

\section{Declarations}

Authors' contributions Jianliang Sun: Conceptualization, 
Writing-Original draft. Mingze Yan: Methodology, Experimental planning, Data processing. Mingyuan Li: Investigation, Validation. Tongtong Hao: Reviewing and Editing.

Funding The authors are grateful for the supports of Natural Science Foundation of Hebei Province (E2020203029, 202160201010289), The central government guides local science and technology development funding projects (206Z1601G).

Data availablility All data generated or analyzed during this study are included in this published article.

Code availability Not appicable

Ethics approval Not applicable

Consent to participate Not applicable

Consent for publication Not applicable

Competing interests The authors declare that they have no known competing interests or personal relationships that could have appeared to influence the work reported in this paper.

\section{References}

[1] G. D. Wang, Flatness Control and Flatness Theory, Metallurgical Industry Press, Beijing, China, (1986).

[2] H. X. Yu, H. M. Liu, Y. H. Xu and D. C. Wang, Interpretation of national standards for cold rolled strip shape detection and control system, Iron \& Steel, 54 (10) (2019) 52-57.

[3] H. Zhao, Research on flatness control system for a Sendzimir mill, Northeastern University, (2012).

[4] Q. D. Zhang, C. Dai, J. Wen, X. F. Zhang and J Qin, Simulation and analysis on shape control behavior of 20-h Sendzimir mill, Steel Rolling, 30 (03) (2013) 1-6.

[5] Y. F. Liu, Y. Huang, X. H. Zhao, Y. B. Sun and D. Yan, Analysis

12 on characteristics of traversing influence of the first intermediate roll in Sendzimir twenty-roller Mill, Heavy Machinery, (1) (2013) 2-6.

[6] S. N. Dai, The research based on theory of twenty-high roll mill rapid analysis model of shape, Yanshan Unversity, (2014).

[7] Z. W. Yuan, Z. K. Ren, H. Xiao and C. Yu, Plate shape control of ultra thin strip rolling for 20-high mill, Journal of Central South University(Science and Technology), 48 (04) (2017) 860-866.

[8] Z. Y. Guo, Simulation analysis of plate profile control of the newtype twenty-high rolling mill, Yanshan University, (2017).

[9] Z. B. Lin, Z. Y. Duan, J. C. Lian, F. C. Xue, D. X. Luo and M. Tian, Journal of Iron and Steel Research, 9 (3) (1997) 60-63.

[10]H. M. Liu, K. R. Ding, X. D. Li, G. B. Jiang, Theoretical computational method of shape standard curve, Journal of Mechanical Engineering, 44 (8) (2008) 137-142.

[11]Y. B. Sun, H. M. Liu, D. C. Wang and Y. Peng, Flatness pre-set control method based on thickness standard curve, Journal of Yanshan University, 35(1) (2011) 29-34.

[12]J. Chen, Research and application of target flatness setting technology for cold rolling mill, World Iron \& Steel, 13(3) (2013) 49-53.

[13]Z. X. Zhao, Research on the shape target curve setting model, Yanshan University, (2014).

[14]C. G. Hao, Y. Y. Ma, S. Q. Cao, Q. S. Zhao, S. Y. Huang and L. P. Su, Effects of two different target curves on true flatness for cold-rolled strip, Aluminium Fabrication, (5) (2017) 17-20

[15]Z. Q. Zhou, Y. Lam, P. F. Thomson and D. D. W. Yuen, Proceedings of the Institution of Mechanical Engineers, Part B: Journal of Engineering Manufacture, 221(2) (2007) 241-254.

[16]R. Usamentiaga, D. F. Garcia, D. González, and J. Molleda, Compensation for uneven temperature in flatness control systems for steel strips, 2006 IEEE Industry Applications Conference-Forty-First IAS Annual Meeting, Tampa, Florida, USA (1) (2006) 521-527.

[17]L. S. Neto and T. Ayhan, Coil build up compensation during cold rolling to improve off-line flatness. Light Metals. 2011 (2011) 621-624.

[18]X. W. Kong, J. Z. Xu, J. Shi and G. D. Wang, Profile and flat control system of hot rolled strip,Journal of Northeastern University(Natural Science), 23 (7) (2002) 683-686.

[19]L. Z. Liu, C. Lu, X. H. Liu, G. D. Wang, New crown setup model of CVC hot strip mill. Journal of Northeastern University (Natural Science), 21 (1) (2001),95-98. 
[20]D. Z. Liu, A. R. He, J. Shao and C. C. Chen, Strategy of crown distribution based on flatness priority in finishing rolling,Journal of Central South University(Science and Technology), 51 (11) (1999) 3253-3259.

[21]Z. Z. Zheng, Y. Peng, H. M. Liu, A new strip element variation method for analysing lateral flow of metal and transverse distribution of front tension stress of cold rolled strip, Journal of Iron and Steel Research, 11 (5) (1999) 21-25.

[22]H. M. Liu, Theoretical and Experimental Studies on The Transverse Distribution of The Rolling Pressure, Frictional Stress and Tension in 4-High Cold Strip Rolling Mill, Yanshan University, (1988).

[23]H. M. Liu, Y. Peng, Y. P. Chu, Strip element method for shape discrimination of strip rolling, Journal of Yanshan University, 26 (2) (2002) 95-98.

\section{Author information}
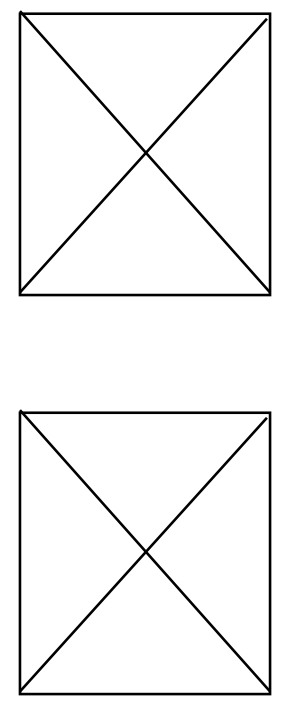

Jlanliang Sun is a professor of school of Mechanical engineering, Yansan University, Qinhuangdao, China. His research interests include Intelligent on-line monitoring and fault diagnosis technology for mechanical equipment, diagnosis and control theory of steel products.

Mingze Yan is a master of school of Mechanical engineering, Yansan University, Qinhuangdao, China. His research interest is flatness control and flatness theory. 